\title{
ERMSAR-2015 conference of SARNET in the frame of the NUGENIA Technical Area 2
}

Despite accident prevention measures adopted in present nuclear power plants (NPP), some accidents, in circumstances of very low probability, may develop into severe accidents with core melting and plant damage and lead to dispersal of radioactive materials into the external environment, thus constituting a hazard for the public health and for the environment. This risk was unfortunately underlined by the Fukushima-Daiichi accidents in J apan in March 2011.

The SARNET network of excellence (Severe Accident Research NETwork), coordinated by the Institut de Radioprotection et de Sûreté Nucléaire (IRSN, France), has been launched in 2004 and co-funded by European Commission in the framework of the $6^{\text {th }}$ and $7^{\text {th }}$ Research and Development Framework Programmes until 2013. The aim was to better coordinate the national efforts in Europe, optimising the use of the available expertise and of the experimental facilities, in view of resolving the remaining issues for enhancing the safety of existing and future NPPs. This was a success with consolidation of the sustainable integration of the European severe accident research capacities and significant research achievements. Mid-2013, the network has been fully integrated in the NUGENIA European association (see www. nugenia.org) that addresses R\&D on Generation II and III nuclear power plants. The SARNET activities have continued in the NUGENIA Technical Area $\mathrm{N}^{\circ} 2$ (TA2) "Severe Accidents", still coordinated by IRSN. This TA2 encompasses the former network activities but also extends them to the issues of "emergency and preparedness response" and "severe accident impact on the environment". The main TA2/ SARNET activities are share of knowledge through technical workshops, elaboration of new $R \& D$ projects, organization of periodic ERMSAR (European Review Meeting on Severe Accident Research) conferences, and organization of education and training courses.

The $7^{\text {th }}$ ERMSAR conference was hosted by the Commissariat à I'Energie Atomique et aux Energies Alternatives (CEA) in Marseille (France) from 24 to 26 March 2015. The Technical Programme Committee involved eight persons from diverse organizations (CEA, CIEMAT, ENEA, IRSN, J SI, KIT, Pisa University). It was the first ERMSAR conference to be organized under the auspices of NUGENIA. It gathered 165 participants from 54 organizations and 21 countries (including, out of Europe, Japan, Russia, USA and Korea), confirming its status as a leading international event on major nuclear reactor accidents. Fifty-one papers and eighteen posters were presented and significant time was allocated after each presentation for questions and open discussions.

During the Plenary Introduction Session, four invited papers were presented, addressing respectively the NUGENIA Association, the EURATOM research activities related to severe accidents within HORIZON 2020 frame, the major issues on the accident progression of Fukushima-Daiichi plants and the radioecology developments supporting NERIS and ALLIANCE European platforms to cope with consequences of a severe accident. A tribute to Bernard Clément (IRSN), international expert on severe accidents, who passed away in summer 2014, was also presented by Michel Schwarz (retired, formerly Head of IRSN Department of Major Accidents Prevention). Four other papers presented respectively the status of the new ASTEC V2. 1 computer code version, the US NRC severe accident research and the two SAFEST and ALISA European projects on transnational access to experimental platforms (the latter for European and Chinese facilities).

Six sessions were organized: in-vessel corium, ex-vessel corium, source term, containment, severe accident scenarios, and emergency preparedness and severe accident impact to the environment. All topics included both experimental and modelling activities, as well as the assessment of the applicability of simulation codes to plant scenarios. The main highpriority topics of the NUGENIA R\&D roadmap that was released in October 2013 have been addressed. This special issue of Annals of Nuclear Energy journal includes a selection of 
twelve ERMSAR-2015 papers (all papers are available on the TA2/ SARNET website www. sarnet. eu), chosen after a first selection by the Technical Programme Committee and a blind double review.

\section{Session “in-Vessel Corium”}

The $R \& D$ aims at reducing the remaining uncertainties on the possibility of cooling the reactor core structures and materials during a severe accident, either in the core region or in the vessel lower head, so as to limit the progression of the accident. This goal could be achieved either by ensuring the retention and the cooling of corium within the reactor vessel by water injection or at least a slow corium progression and small flow rates of corium release into the containment cavity. These issues are linked to severe accident management (SAM) for current reactors and also for design and safety evaluation of future NPPs. Five over eight papers in this session addressed this issue of "In-Vessel-MeltRetention".

Good examples of a joint work among industry and R\&D actors were the papers on clad oxidation: see "Cladding oxidation during air ingress. Part I: Experiments on air ingress", by J. Stuckert (KIT) et al., and "Cladding oxidation during air ingress. Part II: Synthesis of modelling results", by E. Beuzet (EDF) et al.

The other selected paper for this special issue summarized the knowledge on the BWR cases (including those of the Fukushima-Daiichi reactors). In particular, it underlines the predominant mode of failure to be the failures of penetration tubes through the reactor vessel thickness: see "Severe accident progression in the BWR lower plenum and the modes of vessel failure" by B.R. Sehgal (KTH) et al.

\section{Session "Ex-Vessel Corium"}

The mainly investigated situation is, after a postulated failure of the vessel lower head, the corium presence in a reactor cavity that is initially dry but with the possibility of a water injection later on during the molten-core-concrete-interaction $(\mathrm{MCCl})$. Furthermore, steam explosions may be caused by the fuel-coolant-interaction $(\mathrm{FCl})$ after the corium pouring into the flooded reactor cavity.

The following issues have been addressed in this session's papers, most including an experimental part: $\mathrm{FCl}$, debris coolability, $\mathrm{MCCl}$, core-catchers and thermodynamics. Two relatively new issues were analysed: stratified steam explosions and impact of the concrete rebars on $\mathrm{MCCl}$.

One selected paper reviewed different heat transfer correlations with corium in $\mathrm{MCCl}$ situations, in view of recent experimental work and proposed new correlations: see "Molten Corium Concrete Interaction: investigation of convective heat transfer in a pool with gas sparging" by M. Bottin (CEA).

The other selected paper presented the impact of the corium composition and properties on the corium interactions both with the reactor vessel and with the concrete basemat: see "Experimental contribution to the corium thermodynamic modelling" by A.Quaini (CEA) et al.

\section{Session "Containment"}

The $R \& D$ focus is on the threat to the containment integrity caused by highly energetic phenomena, particularly steam explosion and hydrogen combustion. Hydrogen combustion (deflagration and detonation) may be caused by the ignition of a gas mixture with high local hydrogen concentrations, which may be due to the imperfect mixing of the containment atmosphere. The main activities in the FP6 and FP7 SARNET projects were the performance of benchmarks that have now been completed.

Two of the three session's papers addressed the behaviour of passive auto-catalytic recombiners, one on experiments and the other one on the validation of a dedicated code. 
The selected paper showed the global capability of 3D applications of Computational Fluid Dynamics (CFD) codes for containment atmospheric flows in different experiments (German THAI and French MISTRA facilities): see "A comparative assessment of different experiments on buoyancy-driven mixing processes by means of CFD" by S. Kelm (J uelich) et al. These flows are mostly driven by atmosphere density differences due to temperature and or concentration gradients. Furthermore, this work underlined also a significant impact of the modelling of the near-wall gradients as well as of the definition of the wall boundaries and initial conditions.

\section{Session "Source Term"}

The thirteen papers presented in this session focused on reducing the uncertainties associated to estimations of radioactive releases towards the NPP external environment. The main emphasis was on iodine and ruthenium nuclides, given their high radio-toxicity and volatility. Ten papers over thirteen concerned some experimental work.

One selected paper for this journal's special issue addressed the criteria for Filtered Containment Venting Systems (FCVS) implementation in NPPs: see "Methodology developed for the definition of the design parameters and associated safety criteria of the Filtered Containment Venting Systems for Belgian NPPs" by P. Dejardin (GDF-SUEZ) et al. The FCVS key parameters (pressure range, venting flow...) have been assessed through a code chaining between MELCOR core degradation calculations and ASTEC containment and iodine ones.

The second selected paper presented the final analysis of a benchmark that started in the SARNET2/ FP7 project but was completed in 2014: see "SARNET benchmark on the Phébus FPT3 integral experiment on core" by M. Di Giuli, University of Bologna, et al. This benchmark was carried out on the basis of the Phébus FPT3 experiment for assessing the predictive ability of present severe accident codes from core degradation to iodine behaviour in-containment. Different phenomena were quite well predicted, such as core degradation and hydrogen production, volatile fission product release, and thermalhydraulics and aerosol physics in the containment. Nevertheless, this exercise showed that some models still need improvements, such as the iodine chemistry in circuits and containment.

\section{Session "Severe accident scenarios"}

The eight papers in this session addressed the prediction capabilities of several computer codes (mainly ASTEC, MAAP and MELCOR) as well as phenomenological aspects. Half of them dealt with the modelling of in-vessel phenomena, corium propagation in LWRs (Light Water Reactor) and hydrogen generation during a loss of coolant accident in a spent fuel pool.

The selected paper presented the main features of the new major version V2.1 of the ASTEC integral simulation code, developed by IRSN in collaboration with GRS, which is considered as the European reference code due to the continuous capitalization of severe accident knowledge: see "Focus on the main modelling features of ASTEC V2.1 major version" by P. Chatelard (IRSN), et al. This version V2.1 includes new models such as the reflooding of degraded cores and BWR and CANDU core degradation models.

\section{Session "Emergency preparedness and severe accident impact to the environment"}

This new Topic in ERMSAR conferences has received a good success since more than 75 persons attended this session in average. The session featured four papers that addressed the Fukushima-Daiichi accidents and some experimental and theoretical studies about radionuclides behaviour in atmospheric aerosols.

The first two papers tested against Fukushima data the post-accidental risk models, with emphasis on uncertainty analysis and the ambient dose rate dynamics in the terrestrial affected area: see the selected paper "Uncertainty analysis in post-accidental risk 
assessment models: An application to the Fukushima accident" by M. Sy and M. SimonCornu (IRSN).

The last two papers focused on aerosols containing radionuclides, in particular assessing the influence of the electric charge on the wash-out efficiency by rain drops and scavenging by rain at a microphysical scale: see the selected paper "Influence of electric charges on the washout efficiency of atmospheric aerosols by raindrops", by M. Sow and P. Lemaitre (IRSN).

\section{Conclusions and SARNET perspectives}

The SARNET network activities are continuing in NUGENIA frame. Indeed, already some years ago, there was a reorientation from pure knowledge-based $R \& D$ towards $R \& D$ for prevention and mitigation of severe accident consequences (as already underlined by ongoing EURATOM projects that are linked to TA2/SARNET). However, for the future, the usability of the $R \& D$ results must be analysed and probably improved.

The trend is also now to establish closer links with other international communities: with radioprotection and emergency (NERIS, ALLIANCE), with the SAMG (Severe Accident Management Guidelines) community, for example through more papers on plant applications, esp. by utilities or industry, and with the education and training community (such as European Nuclear Education Network (ENEN) or European Nuclear safety Training and Tutoring (ENSTTI)) for further development of expertise in the nuclear fields.

The next ERMSAR conference will be hosted by the Polish National Center for Nuclear Research (NCBJ) in Warsaw (Poland) in spring 2017. This 24-month period will allow accounting for the outcomes of a lot of ongoing $R \& D$ projects in FP7 or in OECD framework and to favour, as much as possible, joint synthesis papers by several partners on severe accidents key issues.

\section{Acknowledgements}

All the actors of the ERMSAR-2015 conference must be acknowledged, in particular the CEA/Cadarache host team (especially Magali Zabiego) and the Technical Programme Committee (besides the guest editors below, Christophe J ourneau from CEA, Luis Herranz from CIEMAT (Spain), Felice de Rosa from ENEA (Italy), François Bréchignac from IRSN, Ivo Kljenak from J SI (Slovenia) and Alexei Miassoedov from KIT (Germany)). Last but not least, this special issue would not have been possible without the help of the Elsevier staff.

J ean-Pierre Van Dorsselaere (IRSN, France), TA2/ SARNET coordinator

Sandro Paci (University of Pisa, Italy), responsible for spreading of excellence activities in TA2/ SARNET 